\title{
The insulin glargine dilemma: an opportunity for the diabetes community?
}

\author{
M. Stumvoll • P. P. Nawroth
}

Received: 14 July 2009 /Accepted: 28 July 2009/Published online: 14 August 2009

(C) Springer-Verlag 2009

Keywords Cancer - Corporate governance · Diabetes · Insulin $\cdot$ Pharmaceutical industry

It has happened again. Once more, the patient is left alone; once again, physicians are caught between the conflicting forces of suspicion and company interest, emotions and experience, traditions and personal relationships with industry representatives, colleagues and scientific associations. The scientific associations are expected to help their members navigate through stormy waters in an impartial manner, even in the absence of definitive scientific evidence. Shareholders lose confidence and money. The company loses trust, image - and money. Its management is on the defensive. This is a lose-lose situation for all concerned, including the authors of a paper that required more post hoc analyses than there were original hypotheses [1]. The conclusion? There is more than an insulin glargine dilemma; there is a fundamental breakdown in the interaction between the players in healthcare. The issue at stake goes beyond insulin analogues or diabetes-it is healthcare in general. We believe that this dilemma has offered us the opportunity to rethink and reorganise some of the relationships in the field, and thereby to achieve better patient care and safety.

M. Stumvoll $(\bowtie)$

Department of Medicine, University of Leipzig,

Liebigstr. 20,

04103 Leipzig, Germany

e-mail: michael.stumvoll@medizin.uni-leipzig.de

P. P. Nawroth

Department of Medicine I and Clinical Chemistry, University of Heidelberg,

Heidelberg, Germany

\section{The situation}

Everyone involved in diabetes care currently confronts the dilemma that insulin glargine, a widely prescribed drug that is highly appreciated by many patients [1-5], is under suspicion of promoting cancer. This suspicion cannot easily be disproved or confirmed. Not surprisingly, a very heated debate over inconclusive data has been the result, certainly in Germany, which was among the first countries to have access to insulin glargine. During the course of this debate, patients have understandably become puzzled and distressed, experts have become divided, and associations, committees and boards have busied themselves issuing statements that are not necessarily helpful for practitioners. Statements are followed by counter statements, accusations by excuses. Stockholders lose money, competitors try to capitalise on the uncertainty, and the media duly contribute their share to, or profit from, the confusion.

\section{The evolution of the dilemma}

Was the insulin glargine dilemma inevitable, something bound to happen sooner or later in the course of the classic conflict between the interests of patients, physicians and shareholders? Or is the dramatic loss of share value now facing the company a reason to hope that, despite diverging interests, a common guideline for patient care and company well-being can be developed?

The possibility that insulin glargine might be associated with cancer is not at all new. A highly debated paper about the in vitro mitogenic potency of insulin glargine was published in 2000 [6]. Others followed, some of which refuted, while others confirmed, the original observations [5]. All this came 
9 years before the recent Diabetologia papers that have so shaken the field [1-4]. More remarkable still, it has been known for more than 10 years that insulin binds to receptors other than the insulin receptor, an issue that has haunted the development of all the modified insulins. Furthermore, the bioactivity curves of insulin and IGF-1 and their respective receptors are suggestive of negative cooperativity, but $k_{\text {on }}$ and $k_{\text {off }}$ rates of insulin to the IGF receptor in the presence or absence of insulin glargine have never been systematically studied. A PubMed search conducted on 14 July 2009 using the terms '(glargine OR hoe 901) AND (cancer OR carcinoma OR neoplasm)' yielded an astonishing 16 hits. Among these, with the exception of the recent publications in Diabetologia, not one addresses the possibility of an increased risk of cancer in humans. Interestingly, the search term 'glargine' yielded 781 hits.

\section{The company's strategy}

It may seem surprising, in view of these longstanding concerns, that the company has never released the data needed to address this issue, whether in cell culture systems, animals or in patients. In vitro studies of the cooperativity of receptor-ligand interactions would have been helpful. Presentation of toxicology data in nondiabetic rats, in which a non-hypoglycaemic dose of insulin glargine did not induce mammary tumours, is a good example of miscommunication. The issue at hand is not whether insulin glargine induces cancer (this has never been suggested by any serious scientist), but whether it promotes growth of pre-existing tumour cells. Any attempt on the company's part to evade this issue will be perceived negatively by the scientific community and will be contrasted with the company's activities (and expenditures) related to marketing. The number of hypoglycaemic episodes for a given level of $\mathrm{HbA}_{1 \mathrm{c}}$, for example, is clearly an important issue, but only one among many. It is worthy of note that a head-to-head study comparing the effect of insulin glargine vs conventional insulin on the prognosis of patients following surgery for pancreatic cancer was sponsored by the German Research Foundation and a private charity organisation, not by the company [7]. The prospective study that addressed the possibility of deterioration of diabetic retinopathy with insulin glargine treatment [8] has been presented as evidence that the agent does not promote cancer development [9], but was neither designed nor powered to resolve this issue. The ongoing Outcome Reduction with an Initial Glargine Intervention (ORIGIN) trial will produce information as to the rate of cancer formation in insulin glargine-treated patients, but cannot answer the key question since it has no comparator arm with human insulin [10].
It is unclear why the company never performed — or better still, commissioned - an independent analysis of their data on file. Opinion leaders would find themselves in a much more comfortable position if such studies, even if only in progress rather than complete, had been pursued with the same passion as studies required for marketing purposes.

\section{The core issue}

As we observe the recent responses of scientific associations, experts, the company and the press, it is surprising to note that everything has revolved around cancer. People appear oblivious to the core issue, which is the life of patients with diabetes in all its aspects. The goal of diabetes therapy is to give patients with diabetes a normal life expectancy, free of complications, with a quality of life similar to that of a healthy person. There would be no insulin glargine dilemma if lives allegedly lost to cancer were outweighed by lives saved by lower mortality from diabetic complications (e.g. fewer fatal strokes or heart attacks, fewer complications from diabetic amputations and fewer car accidents from severe hypoglycaemia). Unfortunately, such information is lacking and is not going to be available any time soon. In consequence, a study as limited as the one by Hemkens et al. [1] receives more attention than it might otherwise deserve.

Why has there not been an appropriately designed randomised, controlled comparison of insulin glargine vs human insulin, with clinically relevant morbidity and mortality endpoints (including cancer)? The answer is easy: it simply has not been necessary. Opinion leaders have been willing to recommend this drug, and practitioners to prescribe it, on the basis of circumstantial evidence, i.e. data showing improved quality of life and reduced hypoglycaemia. This willingness is particularly surprising, given that critical discussion eventually resulted in the launch of outcome trials for thiazolidinediones and GLP-1 analogues in diabetes, just as it did with antihypertensives and lipid-lowering agents. There would have been an even greater need for these for the designer insulins.

\section{The opportunities}

We are dealing with a problem of the company's own making, and a problem that the scientific community has failed to prevent. It is impressive to see how scientific associations, shareholders, physicians and patients alike have been equally paralysed by the insulin glargine dilemma. There are no winners in this game, and even those who wish to redeem society from the evils of Big Pharma run the risk of looking foolish should insulin glargine turn out to be innocent. Since 
the financial loss for the company and shareholders will far exceed the costs of appropriate trials, it is obvious that the rules of the game need changing.

We believe that companies must ensure that the early stages of preclinical testing should encompass safety aspects over and beyond the legally required toxicology studies. An atmosphere conducive to constructive criticism from scientists seriously engaged in the field is needed, not just the grooming of key opinion leaders and future speakers. A critical dialogue should continue after it has been approved, and clinicians who express doubts or constructive concerns should be integrated as partners rather than sidelined as enemies. We are not asking for endpoint data at the time of approval. On the contrary, a mature and engaged scientific community might well be able to endorse a relatively early launch of a drug that has passed adequate preclinical scrutiny, provided that an adequate endpoint trial is planned or underway.

A code of 'corporate governance', to be observed by associations, companies and all players in the field, might be one solution. This must go further than regulatory requirements, and should contain rules of conduct for free communication, serious and honest exchange of information, the obligation to base marketing solely on studies that incorporate endpoint trials as early as possible, and require fair marketing behaviour. This would not only help to avoid insulin glargine-type dilemmas in the future, but would also make it more difficult for competitors to exploit such dilemmas for their own marketing purposes.

In chronic diseases such as diabetes, many effective drugs are available. What we now need is definition of subgroups with endpoint data for tailored care (e.g. hypoglycaemiaprone type 2 diabetes), rather than the next 'blockbuster' for use by every patient. This will not only provide added safety for patients and physicians, but will also allow a company to plan its future with greater security.

\section{A disclaimer}

The authors wish to stress that, based on the current data related to insulin glargine and cancer, they side neither with the fear-mongers nor with the trivialisers. As physicians, we are well aware of the fact that not all cases of type 2 diabetes can be treated with lifestyle advice alone, and that a reasoned, responsible and mutually respectful alliance between pharmaceutical industry, associations and physicians is necessary. We also accept that innovation is expensive and that better drugs may entitle a company to higher revenues. We appreciate that pharmaceutical companies are not charity organisations, and that repeated mergers do not provide a secure basis for initiating large-scale safety trials. Nevertheless, for a condition such as diabetes, when pharmacological alternatives exist, it is not unreasonable to ask that post-marketing safety studies should be as ambitious as the approval studies needed to launch the drug in the first place.

\section{A simple conclusion}

If anything is to be gained from the insulin glargine dilemma, it is the opportunity for all concerned to redefine communication and cooperation in an honest, outspoken and interactive manner. We believe that everyone concerned stands to benefit from this: physicians, scientists, regulatory authorities, companies and their shareholders, but, above all, patients.

Duality of interest The authors declare that there is no duality of interest associated with this manuscript.

\section{References}

1. Hemkens LG, Grouven U, Bender R et al (2009) Risk of malignancies in patients with diabetes treated with human insulin or insulin analogues: a cohort study. Diabetologia 52:17321744

2. Jonasson JM, Ljung R, Talbäck M, Haglund B, Gudbjörnsdòttir S, Steineck G (2009) Insulin glargine use and short-term incidence of malignancies - a population-based follow-up study in Sweden. Diabetologia 52:1745-1754

3. Currie CJ, Poole CD, Gale EAM (2009) The influence of glucoselowering therapies on cancer risk in type 2 diabetes. Diabetologia 52:1766-1777

4. Colhoun HM, SDRN Epidemiology Group (2009) Use of insulin glargine and cancer incidence in Scotland: a study from the Scottish Diabetes Research Network Epidemiology Group. Diabetologia 52:1755-1765

5. Smith U, Gale EAM (2009) Does diabetes therapy influence the risk of cancer? Diabetologia. doi:10.1007/s00125-009-1441-5

6. Kurtzhals P, Schäffer L, Sørensen A et al (2000) Correlations of receptor binding and metabolic and mitogenic potencies of insulin analogs. Diabetes 49:999-1005

7. Erbel S, Reers C, Eckstein VW et al (2008) Proliferation of colo357 pancreatic carcinoma cells and survival of patients with pancreatic carcinoma are not altered by insulin glargine. Diabetes Care 31:1105-11

8. Rosenstock J, Fonseca V, McGill JB et al (2009) Similar progression of diabetic retinopathy with insulin glargine and neutral protamine Hagedorn (NPH) insulin in patients with type 2 diabetes: a long-term, randomised, open-label study. Diabetologia 52:1778-1788

9. Rosenstock J, Fonseca V, McGill JB (2009) Similar risk of malignancy with insulin glargine and neutral protamine Hagedorn (NPH) insulin in patients with type 2 diabetes: findings from a 5 year randomised, open-label study. Diabetologia 52:1971-1973

10. The ORIGIN Trial Investigators (2008) Rationale, design, and baseline characteristics for a large international trial of cardiovascular disease prevention in people with dysglycemia: The ORIGIN Trial (Outcome Reduction with an Initial Glargine Intervention). Am Heart J 155:26-32.e6 